\title{
Treatment of Natural Fiber for Application in Concrete Pavement
}

\author{
Anteneh Geremew $\mathbb{D}^{1},{ }^{1}$ Pieter De Winne, ${ }^{1}$ Tamene Adugna Demissie, ${ }^{2}$ and Hans De Backer ${ }^{1}$ \\ ${ }^{1}$ Department of Civil Engineering, Ghent University, Technologiepark-Zwijnaarde 60, Gent, Belgium \\ ${ }^{2}$ Jimma Institute of Technology, Jimma University, Jimma, Ethiopia
}

Correspondence should be addressed to Anteneh Geremew; antjiren@gmail.com

Received 17 December 2020; Revised 14 January 2021; Accepted 30 January 2021; Published 13 February 2021

Academic Editor: Chunshun Zhang

Copyright (c) 2021 Anteneh Geremew et al. This is an open access article distributed under the Creative Commons Attribution License, which permits unrestricted use, distribution, and reproduction in any medium, provided the original work is properly cited.

\begin{abstract}
Concrete crack is one of the main problems observed in concrete technology due to drying shrinkage. Incorporating fibers in concrete production is one of the mechanisms implemented to mitigate cracks. Nowadays, investigators concentrate on different techniques to replace human-made fiber with existing natural fibers for fiber-reinforced composite material. Utilization of natural fiber has an initiation for the development of eco-friendly materials by reducing damages caused by human-made materials and saving nonrenewable resources. Natural fibers are readily and abundantly available, sustainable, and biodegradable, with low cost and low density, and have superior specific properties. Nevertheless, there are some limitations of natural fiber compared to human-made fiber. Consequently, significant energy was applied to alter natural fiber's surface and morphology using physical, chemical, and biological treatment techniques to overcome the limitation. The primary intention of surface treatment is to modify the bond between the fiber surface and the polymer matrix. However, based on this literature review, there were no specific treatment techniques to be followed to select the best one from the others as criteria. It should include all parameters to consider starting from the stage from the cradle to the grave, cost of chemicals, transportation, and labors, including energy consumption and effluent energy. Additionally, their environmental effect also investigated in detail to compare each other.
\end{abstract}

\section{Introduction}

Concrete was the most extensively used building material worldwide among the materials utilized in all types of civil engineering works [1] such as concrete pavement, concrete domes, apartments, and bridges. One of the applications of concrete is to be utilized in the construction of a rigid pavement due to its several advantages when compared to flexible pavement such as its durability, ability to resist against unexpected traffic load, serving a long time with low repairing cost, and favorability in different environmental conditions [2], but there was some drawback of concrete such as a little tensile strength, limited ductility, and little resistance to early cracking; there is also structural crack build-up particularly before loading due to drying shrinkage or other causes of volume change [3].

According to [4], most of the new concrete cracks observed after five days of placing the concrete as a structure and its early full crack recognize up to 60 days of the age of concrete on the face of casted concrete mainly by variation of moisture, temperature, and poor mix design. Therefore, taking a slab as a counterexample to observe a crack, it takes more than a week to observe a visible crack on the bottom. In general, even by considering all the parameters required during the production of concrete for different applications worldwide, a different defect was observed, starting from a few days of the casting of concrete up to a structure's design life. This is why researchers are looking for an alternative mechanism to solve concrete problems by dispersing fibers in concrete production for different applications. Nowadays, natural fibers are utilized for different industrial applications for self-weight reduction for automotive aerospace due to their advantages such as being cheaply available; in abundance, it controls the ecosystem of the environment, being biodegradable and sustainable with low density and high specific properties [5]. Therefore, this review mainly emphasizes the utilization of surface treatment techniques to enhance the mechanical property of natural fibers and their 
applicability in concrete, especially in civil infrastructure construction as a crack arresting mechanism of concrete during a structure's intended life.

One of the significant reasons for cracking in early-age concrete is the volume changes due to the temperature difference and stress growth throughout the toughening of concrete or moisture variations during the hardening process [6]; this makes the concrete structure unsafe for its intended purpose. Researchers worldwide categorize the cause of concrete cracks based on drying shrinkage cracks and settlement cracks [6-8] by exothermic hydration process of cement during hardening as well as with moisture exchange with the environment, while other researchers clustered the concrete cracks based on the appearance of cracking to be observed such as random cracking due to excess water in the mix, map cracking by drying shrinkage, and concrete overfinishing, transverse cracking caused by contraction or shrinkage as the concrete cures and gives up its moisture content, corner cracking by unequal drying shrinkage, and reentrant crack mainly by high-stress concentration around a joint [9-12]. In addition to this, for further understanding the crack characteristics which were shown mostly on the face of concrete structure not only restricted to early-age concrete but also incorporated in the rigid concrete during its design life due to different factors of environment and loading conditions [4], therefore, it is important to understand types of crack, crack patterns or characteristics, their causes, and the preventive measures to control the cracks $[11,12]$ as shown in Figures 1-7 during maintenance and rehabilitation based on standard specification procedures.

Researchers have studied increasing concrete's toughness by integrating a dispersed fiber in the concrete matrix to overcome the cracks and defects observed on a concrete structure. The experimental results have been accepted as the best remedial for improving energy absorption, stiffness, and mechanical property compared to usual concrete. Also, it is one mechanism of the crack resistance or crack arrest in concrete during its design life [13-15]. This technique has been used at an earlier time for strengthening the inelastic composite for the construction material. Spread fibers can avert cracks and their propagation differently as crack arrester mechanism in brick production for house construction [16]. Therefore, the use of dispersed fiber in the concrete matrix as a construction material utilized on various occasions shows that its results have improved mechanical properties compared to ordinary concrete property [17], such as flexural strength and compressive strength.

\section{Natural Fiber}

Fibers are a small-short, distinct strengthening material prepared by various materials such as steel, plastic, glass, carbon, and natural constituents in several shapes and sizes for different applications [18] such as composite parts for automobiles and aerospace. Natural fibers were grouped based on their sources into subsequent clusters: animal, mineral, and plant, as illustrated in Table 1. Among these, plant fibers are the utmost usually admitted fiber by the

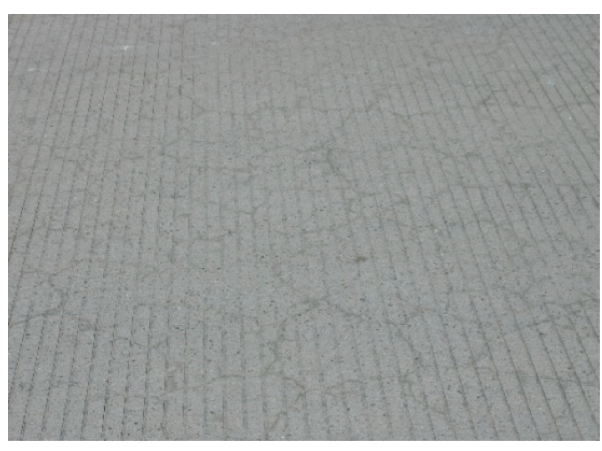

FIgURE 1: Map cracking (crazing) [12].

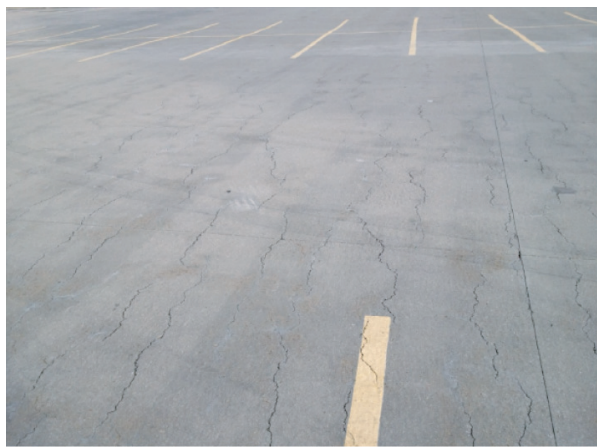

FIGURE 2: Plastic shrinkage cracking [12].

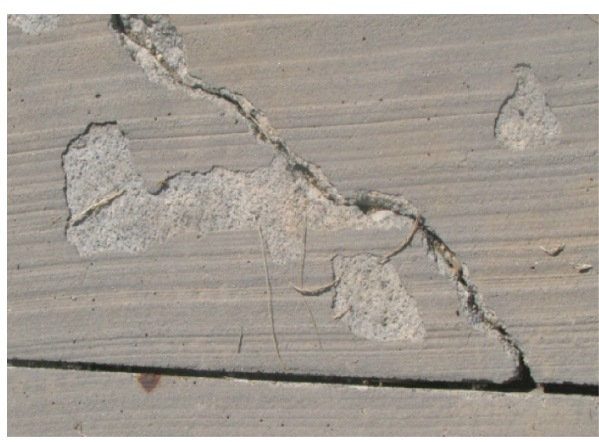

Figure 3: Scaling [12].

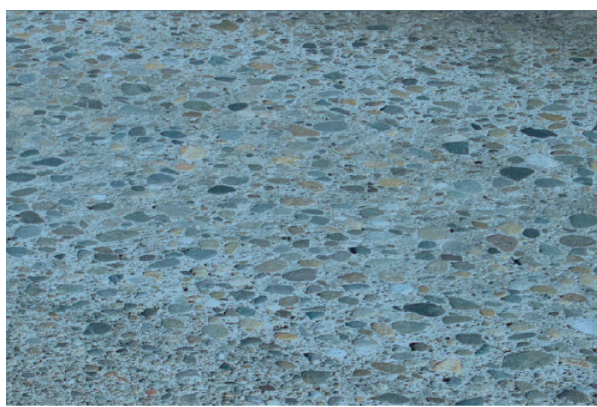

FIGURE 4: Surface polishing [12]. 


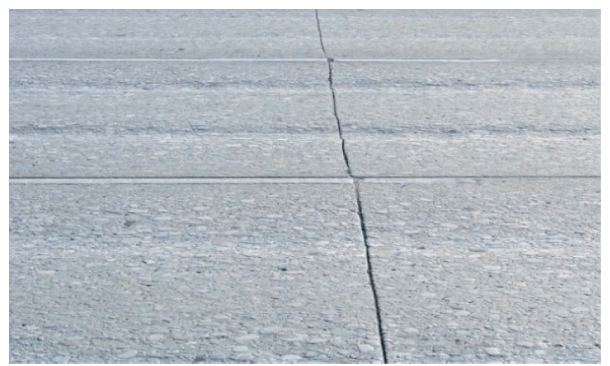

FIGURE 5: Surface wear in the wheel paths [12].

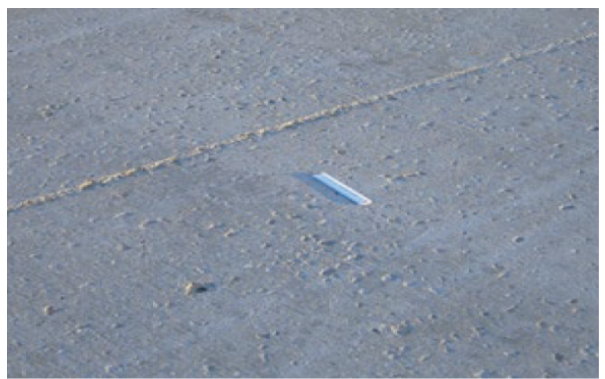

FIgURe 6: Popouts or mortar flaking [12].
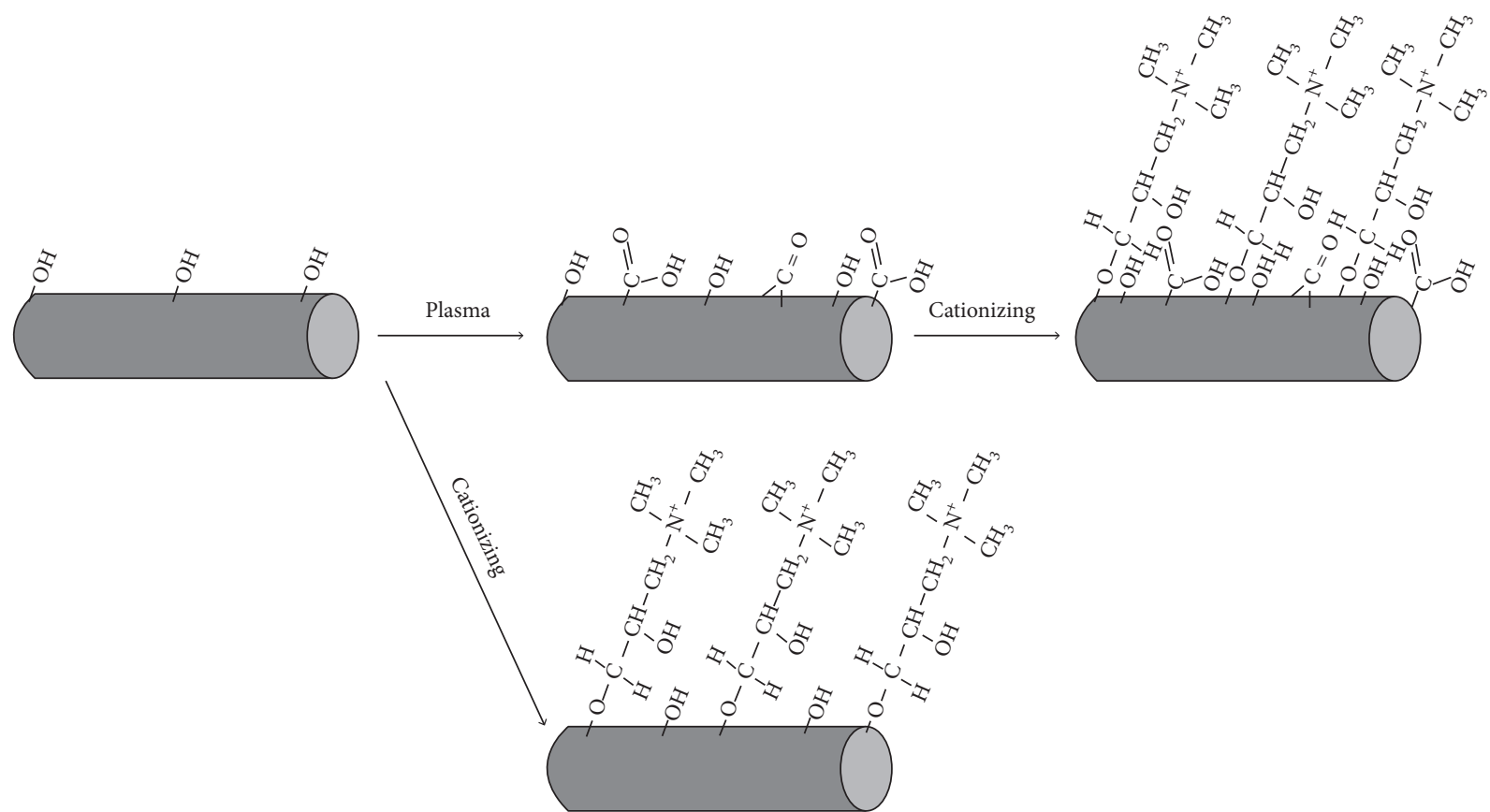

FigURE 7: Effects of plasma and cationizing manners in the surface functionalization of the cellulose constituting the cotton fiber [47].

manufacturing for different applications and a current crucial research area for scholars worldwide to replace synthetic materials and nonrenewable resources. This is mostly because they have insignificant growth age, low cost, illimitability, eco-friendly materials to the environment, and broader availability [19]. This specific review mainly focuses on the plant fibers (Cellulose/Lignocellulose), but the others have been restricted to the industrial application due to toxic or health problems for human beings and limited usages or resources. Natural fibers in nature have numerous paybacks over artificial fibers such as accessibility, low cost, low density, good modulus-weight ratio, high acoustic damping, lower industrial energy expenditure, low carbon footprint, and being decomposable [20]. Other researchers give more striking pieces of evidence for clear benefits such that their cost is much less when compared to other materials during composite production, and it requires fewer energy requirements than traditional reinforcing fibers such as glass and carbon [21]. Conversely, natural fibers have some limitations due to the lower reliability of properties in nature 
Table 1: Natural fiber classification [19]].

\begin{tabular}{|c|c|c|c|}
\hline \multicolumn{4}{|c|}{ Natural fiber classification } \\
\hline \multirow{10}{*}{ Natural fiber } & \multirow{7}{*}{ Cellulose/lignocellulose } & Bast & Flax, hemp, jute, kenaf, ramie \\
\hline & & Leaf & Abaca, banana, pineapple, sisal \\
\hline & & Seed & Cotton, kapok \\
\hline & & Fruit & Coir \\
\hline & & Wood & Hardwood, softwood (e.g., eucalyptus) \\
\hline & & Stalk & Wheat, maize, oat, rice \\
\hline & & Grass/reed & Bamboo, corn \\
\hline & \multirow{2}{*}{ Animal } & Wool/hair & Cashmere, goat hair, horsehair, lamb wool \\
\hline & & Silk & Mulberry \\
\hline & Mineral & - & Asbestos, ceramic fiber, metal fiber \\
\hline
\end{tabular}

and their excellence. This fiber has a radical inconsistency of physical and mechanical properties, more excellent humidity absorption, less stability, lower strength, and lower processing temperature [22-24].

2.1. Chemical Composition of Natural Fibers. The chemical composition of natural fibers consists of cellulose microfibrils in amorphous lignin and hemicellulose composition matrix. The lignocellulose cell wall looked up as naturally happening as a compound structure of spirally oriented form with numerous biochemical mixtures [25]. The fundamental chemical conformation of plant fibers is lignocellulose (cellulose, hemicellulose, and lignin), and the quantity of these constituents varies from plant to plant because of age, species, and also being somewhat dissimilar from portions of the same plant [26]. The topographic nature and climate discrepancy affect its chemical composition of cellulose fibers [27]. Table 2 demonstrates the variety of the typical chemical elements of the wide availability of plant types. Cellulose is a linear macromolecule comprising D-anhydroglucose iterating items linked by $b-1$, four glycosidic linkages. It delivers strength, toughness, and structural constancy for the plant. Hemicelluloses are branched polymers holding five- and six-carbon sugars of several chemical structures; lignin is an amorphous, crosslinked polymer network containing an asymmetrical group of differently joined hydroxy- and methoxy-substituted phenylpropane parts [28]. Lignin is not as much cellulose but a chemical epoxy resin within and between the fibers. Pectins are multifaceted polysaccharides; the principal chains contain an improved polymer of glucuronic acid and rhamnose residues. Their side chains are plentiful in rhamnose, galactose, and arabinose sugars. Calcium ions often cross-link the chains; they recover structural honesty in pectin-rich zones. Lignin, hemicellulose, and pectin together gather as matrix and epoxy resin to grasp the cellulosic framework structure of the most common chemical composition of natural fiber composite [28-30].

Currently, researchers' awareness increases for effective and economical utilization of the entire plant fibers as the possibility of making better quality fiber-reinforced polymer composites for structural and construction material and other purposes. Due to the abundance of natural resources in a wide range globally, this leads to the development of unusual materials instead of human-made materials [31].
Some researchers have been exploring the opportunity to utilize natural fibers to replace human-made fibers in fiberreinforced composites. Natural fibers have numerous properties such as low density, low cost, sustainability, high specific properties, and biodegradability. Nevertheless, they have some shortcomings while operating in compound materials such as low compatibility with various matrices, high moisture absorption, and swelling property that indicates the establishment of cracks in brittle matrices [32-34]. Natural fibers provide a remarkable property during the last formation of composite output, significantly when associated with the atmosphere's protection, such as their capability to be biodegradable, renewable, and small abrasive and harmful [35]. Therefore, some benefits related to natural fibers' usage as strengthening in plastics are their nonabrasive nature, biodegradability, low energy consumption, and low cost.

Furthermore, natural fibers have low density and high specific properties. The specific mechanical properties of natural fibers are like the traditional reinforcements [36]. Hence, inherent properties of natural fibers can fulfill the requirement of the international market [37]; specifically, manufacturing has a concern of a self-weight reduction (i.e., automotive [38], aerospace) for industrial products. That is why scholars are looking for potentially replacing nonrenewable human-made fibers with natural fibers [39].

Still, the hydrophilic nature of natural fibers is a foremost disadvantage for their application as reinforcement for composite manufacture; in addition to this, their weak moisture resistance of natural fibers that lead to incompatibility with different matrix fibers and poor wettability with hydrophobic polymers, and this natural property reduced the interaction bonding at the fiber-matrix interface [40].

Therefore, to utilize natural fibers for different applications for structural and nonstructural composite materials, their inherent properties should be modified to accelerate adhesion to other matrices as composite and avoid their limitation for the required application.

\section{The Value of Improving the Characteristics of Natural Fibers}

Currently, one of the challenges facing the researchers and industrial sector to fully apply natural fiber for the different applications as a composite material was its disadvantage, 
TABle 2: Chemical composition of some common natural fibers [30]].

\begin{tabular}{|c|c|c|c|c|}
\hline Fiber & Cellulose (wt. \%) & Lignin (wt. \%) & Hemicellulose (wt. \%) & Wax (wt. \%) \\
\hline \multicolumn{5}{|l|}{ Bast } \\
\hline Flax & 71 & 2.2 & $18.6-20.6$ & 1.7 \\
\hline Hemp & $70.2-74.4$ & $3.7-5.7$ & $17.9-22.4$ & 0.8 \\
\hline Jute & $61.0-71.5$ & $12.0-13.0$ & $13.6-20.4$ & 0.5 \\
\hline Kenaf & $31.0-39.0$ & $15.0-19.0$ & 21.5 & - \\
\hline Ramie & $68.6-76.2$ & $0.6-0.7$ & $13.1-16.7$ & 0.3 \\
\hline \multicolumn{5}{|l|}{ Leaf } \\
\hline Abaca & $56.0-63.0$ & $7.0-9.0$ & $20.0-25.0$ & 3 \\
\hline Curaua & 73.6 & 7.5 & 9.9 & - \\
\hline Henequen & 77.6 & 13.1 & $4.0-8.0$ & - \\
\hline Pineapple & $70.0-82.0$ & $5.0-12.0$ & - & - \\
\hline Sisal & $67.0-78.0$ & $8.0-11.0$ & $10.0-14.2$ & 2 \\
\hline \multicolumn{5}{|l|}{ Seed/fruit } \\
\hline Coir & $36.0-43.0$ & $41.0-45.0$ & $0.15-0.25$ & - \\
\hline Cotton & 82.7 & - & 5.7 & 0.6 \\
\hline Oil palm & 65 & - & 29 & - \\
\hline \multicolumn{5}{|l|}{ Grass } \\
\hline Bagasse & 55.2 & 25.3 & 16.8 & - \\
\hline Bamboo & $26.0-43.0$ & $21.0-31.0$ & 30 & - \\
\hline \multicolumn{5}{|l|}{ Straw } \\
\hline Rice & $41.0-57.0$ & $8.0-19.0$ & 33 & $8.0-38.0$ \\
\hline Wheat & $39.0-45.0$ & $13.0-20.0$ & $15.0-31.0$ & - \\
\hline \multicolumn{5}{|l|}{ Others } \\
\hline Rice husk & $35.0-45.0$ & 20 & $19.0-25.0$ & $14.0-17.0$ \\
\hline
\end{tabular}

such as weak fiber-matrix interfacial connection, week usability, water absorption, and moisture absorption. The hydrophilic nature of the natural fibers affected the weak interfacial interface between the polymer matrix and the fiber. Therefore, to optimize the fibers' mechanical properties for the intended purpose, the limitation of natural fibers should be avoided by using chemical treatment techniques to improve the surface morphological of the fibers to avoid unwanted materials from the surface of fibers [41-44].

3.1. Surface Modification Techniques. Researchers are currently focusing on the different techniques to change natural fibers' surface for diverse industrial application [32]. Before utilizing as a compound material, the natural fibers' surface morphological characteristics should be modified in order to upsurge the surface unevenness of the fibers, to enrich the interfacial interaction between the matrix and the fiber, and also to avoid the shortcoming of natural fiber that comprises weak fiber-matrix interfacial attachment, low wettability, water absorption, and moisture absorption. The week interfacial interaction of polymer matrix and fiber occurs due to the hydrophilic nature of natural fiber [40]. Therefore, that was why we should improve natural fibers to be adopted for application as a compound material. Moreover, mostly used techniques to enhance the mechanical characteristics and fiber's surface were discussed here.

3.1.1. Physical Techniques. This is the simplest method of fiber modification used by the human being adopted earlier for a different utility such as ropes, clothing, and hunter- gatherer used by the help of physical processes of plant fiber packages which were disconnected to distinct threads to the essential purpose to obtain fibers. Therefore, a typical example of physical techniques was plasma treatment, which was effectively engaged to adapt the surface of numerous natural fibers by human beings, and there was an improvement in mechanical properties of natural fibers when carrying plasma treatment [45]. It is a process by which surface polymer functional clusters were replaced by unlike atoms from ions in the plasma to raise surface energy. Plasma activation is regularly utilized to make a surface for connection. Surface contact to active species breakdowns the polymer at the surface, generating free radicals. Plasma comprises ultraviolet (UV) radiation at great stages, making new free radicals on the natural fiber surface. Free radicals speedily reply with the material itself due to unsteadiness. This makes the surface create a strong covalent bond between them $[46,47]$ as shown in Figure 7 on the cotton fiber.

Research carried by [48] shows a flexural strength of the compound material equipped with fiber treated by plasma which indicated that approximately $14 \%$ increments matched new fiber amalgams. The plasma treatment carried on cellulosic fibers [49] added activation sites and attachment of polymer deposits; it shows an increase of $70 \%$ fibermatrix interface strength. Nevertheless, the tensile strength of treated compounds was only improved by about $4 \%$ matched to that of raw ones; also, Young's moduli of the composites were increased by $70 \%$, but this method requires much energy during preparation. Therefore, additional research investigation should be needed to reduce the lengthy processing of traditional methods with that of the modern, consistent treatment technology to reduce more energy 
during preparation and also to increase the mechanical property of fibers more than untreated fibers.

3.1.2. Chemical Treatments. Chemical treatments utilized chemical agents to alter the interaction and surface characteristics of the natural fibers by numerous appliances such as the disregarding weak periphery on the strata of fibers, changing the acidity-alkalinity of the fibers, and making reliable and elastic stratum on top of the fiber's surface [25], or a method to boost the contact among the fibers and polymer matrix is commonly carried out by cleaning the wax and lignin from the fiber surface to increase mechanical interconnection and acts as "bridge" the hydrophilic cellulosic fiber and the hydrophobic plastic with functional molecules, which react with both the cellulose $\mathrm{OH}$ and the polymer functional groups [40, 50]. Several handling aids and pairing agents have been utilized to strengthen the spreading and connection of fibers. From this perspective, numerous approaches have been suggested by attempting the artificial biochemical alteration of the fibers and service for polymers adept at pairing with the hydroxyl groups of the surface cellulosic reduction while applying such chemical on their surface. The presence of cellulose in the fiber, hydrophilic in nature, upsets the interfacial attachment between the polymer matrix and the fiber because the matrix is hydrophobic [51].

(1) Alkali Treatment. The researcher frequently uses this for treating natural fibers for different applications with the help of $\mathrm{NaOH}$ solution for a specified duration time. Partly, it eliminates lignin and hemicellulose and entirely eliminates pectin, wax, and other organics from the fibers' surface. After this treatment, additional cellulose molecules are unprotected, enhancing a connection between the fiber and matrix [52]. The quantity of $\mathrm{NaOH}$ concentration, drying temperatures, and the treatment time are all leading issues that govern compounds' mechanical properties during the last stage [53]. Different procedures were adopted in [54] to consider the effect of alkali treatment on various natural fibers without mechanical conduction tests on composite material; this study was energetic in understanding its effect on the fibers' crystallinity index. These studies indicated that the lower the concentrations of alkali treatment, the higher the crystallinity index, which is selected for promoting better fiber to matrix bonding during composite material formation. The studies confirmed this conclusion carried out by [55]. Alkali-treated pineapple leaf and sisal fibers with 5\% aqueous solution in a polyester resin matrix show a more excellent tensile and impact strength than the ones treated with a $10 \%$ solution. This indicates that the low concentration of the $\mathrm{NaOH}$ solution prompted hydrophobicity in the natural fibers. Additional investigation of scanning electron microscope (SEM) micrographs also showed a higher $\mathrm{NaOH}$ concentration in fiber degradation. However, the mercerization of oil palm fibers with a $5 \%$ alkali solution at ambient temperature resulted in lower tensile strength in their composites with phenol-formaldehyde. Despite that, a $13 \%$ increase in Young's modulus and a 3\% growth in compressive moduli were detected in treated specimens. The compressive strength also increased by $53 \%$ after alkalizations. The hydrophilicity of the PF matrix could explain these results. The hydrophobic treated fibers lose their compatibility with the hydrophilic matrix, and the mechanical properties deteriorate [56]. Also, another research [57] prepared composite materials with alkali-treated hemp and recycled high-density polyethylene (HDPE). The authors observed $56.8 \%$ and $61.7 \%$ enlargement in tensile strength and modulus, respectively. These alkali-treated fiber studies show that the arguments made in [54] are valid. The amount of alkali concentration played an essential function in the resulting composite materials' ultimate mechanical properties.

(2) Silane Treatment. Silane coupling agents possess alkoxy groups that react with the polymer functional group and organofunctional groups that enter into reaction with the cellulose's $\mathrm{OH}$ group. Alkyl bridges connect the silicon atom to the organofunctional groups [52] and a standard modification method of fibers intended for use in composite materials. According to the study [58], sugar palm fibers are treated with $2 \%$ saline and $6 \%$ sodium hydroxide for $3 \mathrm{hrs}$. It indicates an improvement in the boundary interface between the fiber and thermoplastic polyurethane after the treatments. This method works as a combination proxy, and hence, its improvements in mechanical properties are observed in the experiment's result [59]. The surface treatment carried out in [60] on the jute fiber was modified. Silane coupling proxy treatment was performed out in purified water with $5 \%$ silane coupling amount for an hour at $25^{\circ} \mathrm{C}$. Consequently, the samples are dried in the electronic furnace for 24 hours at $50^{\circ} \mathrm{C}$. Therefore, the experimental result shows that the compound's tensile and flexural creep strain by silane treatment was reduced when compared with untreated fibers. Based on various literature studies, the amount of added silane agents varied between 1 and $5 \%$, whereas the hydrolysis period, the extent of silane concentration, temperature, and $\mathrm{pH}$ are the principal aspects influencing the silane treatment's efficiency. This experimental result confirmed that the silane pairing agent's interface altered the fiber and the matrix more resiliently than that of alkaline treatment; this led to composites with greater tensile strength from silanetreated fiber than alkaline-treated fiber [61] due to additional treatment.

(3) Acetylation Treatment. The means of announcing an acetyl group on the fiber surface is executed to shrink the fibers' hydrophilic nature by presuming constancy to the compound material and upsurge the bond fiber-matrix properties. It builds a rigid connection established between the compound constituents; consequently, it creates outstanding composite performance. The $\mathrm{OH}$ groups of the fibers rejoin with the acetyl groups, which makes the fibers further hydrophobic in nature [62]. Furthermore, lignin and hemicellulose comprise the hydroxyl group and react with acetyl groups to develop hydrophobically. Frequently, formerly, the treatment was with glacial acetic acid, and the natural fiber is alkali-treated. Acetylation 
treatment of sisal fiber was stated to enhance the fiber-matrix bond. The steps to be followed encompassed an alkaline treatment, to begin with, followed by acetylation. According to [55]' by considering an acetylation treatment of sisal fibers, then, dewaxed sisal fiber was submerged in $5 \%$ and $10 \% \mathrm{NaOH}$ solution for an hour at $30^{\circ} \mathrm{C}$; the alkaline-treated fiber was saturated in glacial acetic acid for an hour at $30^{\circ} \mathrm{C}$; it was poured and soaked in acetic anhydride encompassing one droplet of concentrated $\mathrm{H}_{2} \mathrm{SO}_{4}$ for $5 \mathrm{~min}$. An experiment conducted in [63] preserved natural sisal fiber with $18 \%$ sodium hydroxide solution, then in glacial acetic acid, and lastly in acetic anhydride having two droplets of concentrated $\mathrm{H}_{2} \mathrm{SO}_{4}$ for one hour. The treated surface of sisal fiber seemingly became heavier and had numerous spaces that provide a well mechanical connection with the polystyrene matrix. A hypothetical prototype of the interface among the sisal fiber and polystyrene compounds has been recommended. Later, preserved cellulose fiber compounds' thermal stability was more remarkable than that of untreated fiber compound because treated fibers' higher thermal stability enhanced better fiber-matrix interactions in composites. Therefore, acetylation cellulose fiber-reinforced polyester composites demonstrate a great bioresistance, but small tensile strength defeat, when related to composites with silane-treated fiber [64].

(4) Maleic Anhydride Treatment. This is one of the most commonly used coupling agents to strengthen the compounds with natural fibers and nonpolar polymers. The compounds' mechanical properties increase as the pairing agent is involved in the fiber surface and integrates a polymer on the other end. The flexural strength of jute-polypropylene increased by $40 \%$ with maleic anhydride-polypropylene treated jute fibers, and also, a $90 \%$ increment on the flexural modulus was observed in the experimental result [65]. Besides being used with virgin raw materials, these coupling agents have also been incorporated in composites with recycled materials. Maleic anhydride grafted polypropylene was used with composites manufactured from recycled waste plastic and waste sawdust, and this combination's mechanical properties were investigated. The result shows improved tensile and compressive and flexural properties of recycled and virgin polypropylene composites with maleic anhydride-polypropylene (MAPP) treatment to their controls [66]. An alternative investigation carried out with wood floorpolyethylene composite, maleic anhydride treatment of the filler, ensued a $50 \%$ upsurge in tensile strength and a $40 \%$ upturn in flexural strength compared to their controls [67]. It concluded that the experimental analysis, maleic anhydride coupling agents could improve cellulosic fillers' adhesion to nonpolar polymers regardless of the polymer type.

(5) Benzoylation Treatment. Benzoylation treatment enhances fiber-matrix connection by a noticeably increment in the strength of compound material, decreasing its water immersion and modifying its thermal stability [68]. During this treatment, the fiber-matrix bonding was improved, and its strength of the composites also increases. Using benzoylation chemical, the fibers were initially preserved with $\mathrm{NaOH}$ mixture for 15 min; then, subsequently, a benzoyl chloride $\left(\mathrm{C}_{6} \mathrm{H}_{5} \mathrm{COCl}\right)$ treatment was carried out. Later, a minute of duration, the fibers remained quarantined and treated with ethanol, and then finally, it was allowed to dry for $24 \mathrm{hrs}$ in an oven at $80^{\circ} \mathrm{C}$; after that, it was washed with distilled water several times [69]. From the experimental analysis, the treated fibers show more thermal stability than that of the untreated fibers. This result is mostly dependent on alkali treatment like other coupling agents; this indicates that alkali treatment is essential for further surface treatment of natural fibers.

3.1.3. Biological Treatments. This method encompasses the utilization of naturally occurring bacteria such as bacteria and fungi. The process was carried out in aqueous atmospheres and it is somewhat low-priced to execute, but regularly, it consumes more time and it pollutes water in nature. The most embraced method of natural fiber treatment is retting treatment. The humiliation of plant organizes retting stalks from the bast fibers' discharge from their fiber packages and distinguishes them from the woody core and epidermis [46]. Throughout the retting process, bacteria (predominantly Clostridia species) and fungi release enzymes to degrade pectin and hemicellulose compounds in the middle lamella among the individual fiber cells. This method was less expensive, energy-intensive, and more ecofriendly than chemical treatments, and it has low scalability and difficulty in controlling the processes, which are the main disadvantages of these kinds of fiber treatment [41].

\section{Other Advantages of Treatments on Natural Fibers}

Besides the enhancement in wettability, biochemical clusters, surface morphology, and tensile strength of the fibers, by modifying their microstructure, the natural fibers' chemical treatments mostly enrich the mechanical belongings of the natural fiber [70]. The interfacial bond was improved by the fiber's chemical treatment between the polymer matrix and the fiber surface, the composites' thermomechanical properties. The subsequent improvement in the tensile strength, the chemical treatment of ramie fibers, has shown the treatment of fibers with saline or alkaline or the combined treatment [71]. One of the implemented practices adopted to diminish the natural fibers' hydrophilic nature in industrial applications by chemical treatment and the matrix improves the adhesion. This is due mainly to removing noncellulosic substances, and the morphological and structural fluctuations can be detected in the treatment of the fibers. The compound's material properties were reported with significant improvement when various chemical treatments and the composites were reinforced with the natural fiber to increase the thermal stability [72].

\section{Comparison in terms of Energy Consumption during Processing}

The more attractive way to compare different natural fiber treatment methods based on a different aspect such as life cycle assessment was the main criteria for selecting more suitable treatment techniques for natural fibers to avoid 
inherent property such as the week characteristics between fiber and matrix and a comparative moistness absorption by keeping the advantage of natural fibers related to human-made fibers. A review study conducted in [73] stated that the comparison method of treatments of natural fibers carried out on the extent of energy spent in the treatment practice (mixing, drying, and wash) and effluent (predefined for management) maleate treatment was selected among the other treatment methods as illustrated in Figure 8. Using this method, there was no consumed specific energy during the treatment process. However, there was no effluent energy during production due to this maleated treatment selected, and other treatment methods consume different types of energy. This study's gap was that there is only one source of data taken from the company regarding energy consumption and effluent energy; also, it did not consider other parameters for comparison. However, other techniques such as the physical (plasma) and biological (enzyme) treatments were not studied due to the absence of adequate evidence concerning the energy intake utilized in these methods, and also currently, there was limited treatment adopted, which was restricted on a small scale in the laboratory.

Therefore, based on this literature review, there were no specific treatment techniques among them while selecting the best one according to criteria. It should include all parameters to consider starting from the stage from the cradle to the grave, cost of chemicals, transportation, and labors, including energy consumption and effluent energy. Additionally, their environmental effects are also investigated in detail to compare each other.

\section{Some of the Applications of Fibers in Concrete Technology}

Due to various kinds of manufacturing in building engineering, the applications of fiber-reinforced concrete materials incorporated in composites are reliable and expanded worldwide, especially in developed countries [74]. Therefore, one of the reasons to use fiber-reinforced concrete as composite material when compared to plain concrete is the fact that it has many characteristics observed in the experimental investigations of different researchers looking for a positive outcome, such as the following:

(i) It acts as a mechanism for crack arresting and crack control as a solution in concrete technology [75]

(ii) It increased flexural strength, postcrack loadbearing capacity, toughness, and viscosity in the fresh state [15]

(iii) It enhanced excellent mechanical performance and its properties such as strength, toughness (rigidity), permanence, and ductility [76]

(iv) It shrinks the specific weight and density in a lightweight invention material that is both energyefficient and cost-efficient in application [74] (v) It avoids the existence of reduction, cracks, spalling, and puffiness in concrete during casting [77]

(vi) Reduction of pavement thickness in the rigid pavement as compared to the plain concrete slab and use of natural fibers, as reinforcement of composites (such as cement paste, mortar, and/or concrete), are economical for increasing their certain properties, for example, tensile strength, shear strength, and toughness [78]

(vii) Higher energy absorption was observed for fiberreinforced foamed concrete compared to the plain foamed concrete, which was attributed to the fibers' enhanced toughness and ductility [79]

The applications of natural fiber composites are found in building and construction, aerospace, sports, and more, such as partition boards, ceilings, boats, office products, and machinery. Most applications of natural fiber composites are concentrated on nonload-bearing indoor components in civil engineering because of their vulnerability to environmental attack. Green buildings are wanted to be ecologically mindful, suitable, and healthy places to live and work. Biocomposite is considered one of the major materials utilized as a part of green materials at this time. It could be categorized, with regard to their application in the building market, into two principal products: firstly, structural biocomposite, which includes bridge as well as roof structure, and secondly, nonstructural biocomposite, which includes a window, exterior construction, composite panels, and door frame [80]. The wide advantages of natural fiberreinforced composites such as high stiffness to weight ratio, lightweight, and biodegradability give them suitability in different applications in building industries and also have good properties of thin-walled elements such as high strength in tension and compression, made of sisal fiber-reinforced composites, which give it a wide area of applications, for instance, structural building members, permanent formwork, tanks, facades, long span roofing elements, and pipe strengthening of existing structures. On the other hand, bamboo fiber can be used in structural concrete elements as reinforcement, while sisal fiber and coir fiber composites have been used in roofing components to replace asbestos. Natural fiber-reinforced concrete products in construction applications like sheets (both plain and corrugated) and boards are light in weight and are ideal for use in roofing, ceiling, and walling for the construction of low-cost houses [34]. Fiber-reinforced concrete increases the static and dynamic tensile strength, energy-absorbing characteristics, and good fatigue strength; nowadays, it is used as overlays of the airfield, road pavement, refractory linings, etc. The isotropic properties of concrete are provided by uniform dispersion of fibers compared to conventional reinforced concrete, so, fiber-reinforced concrete is also nowadays used in the fabrication of precast members like pipes, boats, beams, staircase steps, wall panels, roof panels, and sanitary man-holes covers [81]. 


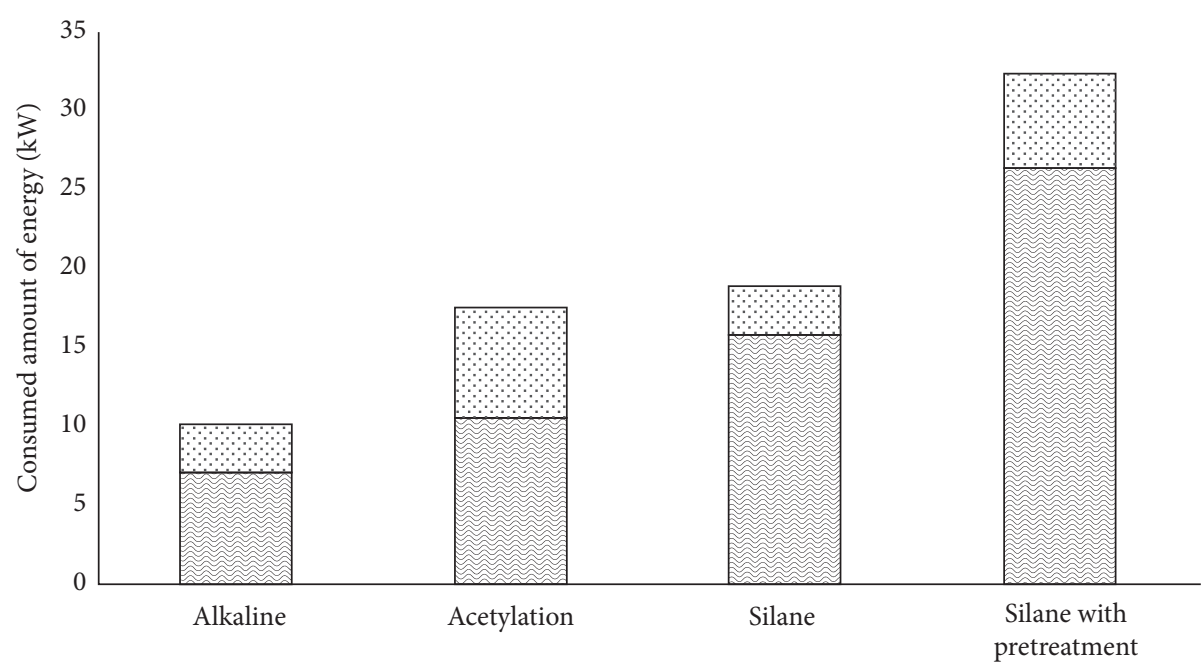

Procedure energy

Effluent energy

FIgURE 8: Energy intake for various chemical treatments per unit of natural fiber [73].

TABLE 3: Applications of the biocomposite [82].

\begin{tabular}{ccc}
\hline & Parts & Material used \\
\hline & Panel & Sisal jute Sandwich composites \\
Applications & Door and panels & Bamboo mat composite \\
& Roof & Jute coir composite \\
& Furniture & Jute pultruded door frames, medium-density composites \\
& Cupboards, wardrobes & Natural fiber-reinforced boards \\
\hline
\end{tabular}

Others mostly utilized the application of natural fiber in the biocomposite material in building materials, as illustrated in Table 3.

\section{Summary and Conclusions}

The application of natural fibers in the composite material is increasing on the industry level due to several advantages it has over synthetic fibers. Natural fibers' surface treatment is crucial to replace synthetic fiber with natural fibers to mitigate global warming. To entirely avoid natural fibers' limitation composites such as weak fiber-matrix interfacial adhesion, water absorption, low wettability, weak interfacial contact between the polymer matrix and the fiber, moisture concentration, and the natural fibers' hydrophilic nature, a chemical treatment was adopted.

According to this literature review, different researchers use different surface modifications based on their availability and interest. However, there were no specific types of chemicals for specific fiber type's treatment from the researchers' point of view. There are different techniques discussed in this literature review, such as physical, chemical, and biological methods. The typical example of physical techniques was that plasma treatment effectively modified various natural fibers' surfaces and significantly improved their mechanical properties. However, it requires a lengthy process to obtain fiber and consumes much energy to produce it. Based on this researchers' investigation, the lengthy process of traditional methods should reduce adopting modern, consistent treatment technology. This significantly reduces the energy required during preparation and increases mechanical property. Several treatment methods are utilized by different researchers in different areas based on their interest and availability of alkali, silane, acetylation, maleic anhydride, and benzoylation. Alkali treatment is one of the earlier used methods for treating fiber supporting $\mathrm{OH}$ chemicals at different concentrations at a specified time to alter the surface of fibers in the final mechanical properties of the resulting composite constituents. At lower alkali treatment concentrations, the higher crystallinity index is selected for promoting better fiber to matrix bonding during composite material formation. Silane treatment acts as a pairing agent that altered fiber and the matrix and was more reliable than alkaline treatment. It creates a composite with a higher tensile strength than alkaline-treated fiber. In order to apply this method, first, the fiber is treated by alkali; that is why there is more improvement than the alkali treatment method. Acetylation treatment establishes an acetyl group on the surface of the fibers, utilized to moderate the hydrophilic nature of fibers by giving a constancy to the composite materials, and upturns the fiber-matrix bond performance by creating a durable connection formation between the composite materials. In addition, it improves thermal stability when compared to untreated fibers. Therefore, this method shows a greater bioresistance and 
TABLe 4: Main advantage and limitation of each treatment technique.

\begin{tabular}{|c|c|c|c|c|c|}
\hline & & & Advantage & Limitation & References \\
\hline \multirow{8}{*}{$\begin{array}{l}\text { Surface } \\
\text { treatment } \\
\text { techniques }\end{array}$} & $\begin{array}{l}\text { Physical } \\
\text { method }\end{array}$ & Plasma method & $\begin{array}{l}\text { (i) It eliminates softly unwanted parts } \\
\text { from a surface layer or develops a } \\
\text { novel functional cluster. } \\
\text { (ii) It successfully modifies the surface } \\
\text { properties and eliminates the } \\
\text { operation of biologically harmful } \\
\text { elements. } \\
\text { (iii) No change occurs in the bulk } \\
\text { properties of treated fibers. }\end{array}$ & $\begin{array}{l}\text { (i) Being degraded and modifying } \\
\text { the surface of fiber arise due to the } \\
\text { etching mechanism that creates pits } \\
\text { on the external fiber zone. }\end{array}$ & {$[83,84]$} \\
\hline & \multirow{6}{*}{$\begin{array}{l}\text { Chemical } \\
\text { treatments }\end{array}$} & & $\begin{array}{l}\text { (i) It successfully removed impurities } \\
\text { (hemicelluloses and lignin). }\end{array}$ & $\begin{array}{l}\text { (i) A large amount of water is needed } \\
\text { for washing and also long } \\
\text { pretreatment resident time. }\end{array}$ & \multirow[b]{2}{*}[85,86]{} \\
\hline & & Alkali treatment & $\begin{array}{l}\text { (ii) It can alter the smooth surface to } \\
\text { be rough fiber surfaces by preparing } \\
\text { well mechanical meshing and more } \\
\text { muscular interfacial strength of the } \\
\text { fiber-matrix. }\end{array}$ & $\begin{array}{l}\text { (ii) Its mechanical property depends } \\
\text { on the percentage of alkali solution } \\
\text { treatment, duration, and } \\
\text { temperature. }\end{array}$ & \\
\hline & & Silane treatment & $\begin{array}{l}\text { (i) It enhances hardiness and lowers } \\
\text { water absorption of the fibers } \\
\text { subsequent in hydrophobic } \\
\text { composites. } \\
\text { (ii)It improves the thermal stability of } \\
\text { the composites. }\end{array}$ & $\begin{array}{l}\text { (i) It is a coupling agent that } \\
\text { depends on the treatment of the } \\
\text { alkali solution. }\end{array}$ & {$[87,88]$} \\
\hline & & $\begin{array}{c}\text { Acetylation } \\
\text { treatment }\end{array}$ & $\begin{array}{l}\text { (i) It improves crystallinity, reduces } \\
\text { water adsorption capacity, and } \\
\text { increases the fiber-matrix adhesion } \\
\text { properties. }\end{array}$ & $\begin{array}{l}\text { (i) It enlarges acetylation, reducing } \\
\text { mechanical properties due to the } \\
\text { degradation of cellulose and } \\
\text { cracking of fibers. }\end{array}$ & {$[89,90]$} \\
\hline & & $\begin{array}{l}\text { Maleic } \\
\text { anhydride } \\
\text { treatment }\end{array}$ & $\begin{array}{l}\text { (i) It increases fiber-matrix adhesion } \\
\text { and thermal stability and also reduces } \\
\text { water. } \\
\text { (ii) It improves the property of } \\
\text { composite material. }\end{array}$ & $\begin{array}{l}\text { (i) It is highly motivated by } \\
\text { compactness, temperature, and fiber } \\
\text { loading. }\end{array}$ & {$[91,92]$} \\
\hline & & $\begin{array}{c}\text { Benzoylation } \\
\text { treatment }\end{array}$ & $\begin{array}{l}\text { (i) It decreases the hydrophilicity, } \\
\text { improves the fiber-matrix bond, and } \\
\text { also enhances the strength of the } \\
\text { composite. }\end{array}$ & $\begin{array}{l}\text { (i) It is a coupling agent that } \\
\text { depends on the treatment of the } \\
\text { alkali solution. }\end{array}$ & {$[87,93]$} \\
\hline & $\begin{array}{l}\text { Biological } \\
\text { treatment }\end{array}$ & $\begin{array}{l}\text { Retting } \\
\text { treatment }\end{array}$ & $\begin{array}{l}\text { (i) It is eco-friendly with surrounding } \\
\text { and has lower energy consumption } \\
\text { during processing excluding or } \\
\text { diluters. } \\
\text { (ii) It improves fiber surface } \\
\text { spotlessness and separated fiber } \\
\text { bundles. }\end{array}$ & $\begin{array}{l}\text { (i) Low scalability is limited to the } \\
\text { laboratory. } \\
\text { (ii) It partly eradicates pectic and } \\
\text { hemicellulose constituents in } \\
\text { cellulose fiber. }\end{array}$ & {$[94,95]$} \\
\hline
\end{tabular}

fewer tensile strength than composites with silane-treated fiber. Maleic anhydride treatment acts as a pairing agent to strengthen the composites with natural fibers and nonpolar polymers and improves cellulosic fillers' adhesion to nonpolar polymers regardless of the polymer type. Benzoylation treatment of fiber improves fiber-matrix adhesion with a noticeably increment in the strength of composite material. Also, it declines its water absorption and enhances its thermal stability. This method mostly depends on alkali treatment results like other coupling agents; this indicates that alkali treatment is essential for further surface treatment of natural fibers. The biological methods are more successful at a laboratory scale than those of an industrial scale; subsequently, various parameters have to be considered and controlled during adopting treatment for surface modification. The advantage and disadvantages of the main treatment techniques are summarized in Table 4.

Therefore, based on this literature review, there were no specific treatment techniques among them while selecting the best one according to criteria. It should include all parameters to consider starting from the stage from the cradle to the grave, cost of chemicals, transportation, and labors, including energy consumption and effluent energy. Additionally, their environmental effect was also investigated in detail to compare each other.

\section{Conflicts of Interest}

The authors declare that they have no conflicts of interest. 


\section{References}

[1] Z. Li, Advanced Concrete Technology, John Wiley \& Sons, Hoboken, NJ, USA, 2011.

[2] M. V. Mohod and D. K. N. Kadam, "A comparative study on rigid and flexible pavement," A Review, vol. 13, no. 3, pp. 84-88, 2016.

[3] L. Fritz, "Cracks and crack control in concrete structures," Pci Journal, vol. 7, pp. 124-145, 1988.

[4] M. Safiuddin, A. Kaish, C.-O. Woon, and S. Raman, "Earlyage cracking in concrete: causes, consequences, remedial measures, and recommendations," Applied Sciences, vol. 8, no. 10, p. 1730, 2018.

[5] M. R. Sanjay, G. R. Arpitha, L. L. Naik, K. Gopalakrishna, and B. Yogesha, "Applications of natural fibers and its composites: an overview," Natural Resources, vol. 07, no. 03, pp. 108-114, 2016.

[6] Springer International Publishing, "Thermal cracking of massive concrete structures," in RILEM State-of-the-Art Reports, E. M. R. Fairbairn and M. Azenha, Eds., vol. 27, Berlin, Germany, Springer International Publishing, 2019.

[7] ACI Committee 224, 224.1R-07: Causes, Evaluation, and Repair of Cracks in Concrete Structures, American Concrete Institute, Michigan, USA, 1998.

[8] M. Nehdi and A. M. Soliman, "Early-age properties of concrete: overview of fundamental concepts and state-of-the-art research," Proceedings of the Institution of Civil EngineersConstruction Materials, vol. 164, no. 2, pp. 57-77, 2011.

[9] A. Mohsen, "ISSA. Investigation of cracking in concrete bridge decks at early ages," Journal of Bridge Engineering, vol. 4, no. 2, pp. 116-124, 1999.

[10] J. E. Hiller and J. R. Roesler, "Determination of critical concrete pavement fatigue damage locations using influence lines," Journal of Transportation Engineering, vol. 131, no. 8, pp. 599-607, 2005.

[11] K. R. Kashyzadeh and N. A. Kesheh, "Study type of cracks in construction and its controlling," IJETAE, vol. 2, no. 8, pp. 1-5, 2012.

[12] D. Harrington, M. Ayers, T. Cackler et al., Guide for Concrete Pavement Distress Assessments and Solutions: Identification, Causes, Prevention, and Repair, p. 500, Iowa State University, Ames, IA, USA, 2018.

[13] K. S. Kene, "Experimental study on behavior of steel and glass fiber reinforced concrete composites," Bonfring International Journal of Industrial Engineering and Management Science, vol. 2, no. 4, pp. 125-130, 2012.

[14] J. I. Daniel, V. S. Gopalaratnam, and M. A. Galinat, Report on Fiber Reinforced Concrete, p. 66, American Concrete Institute, Detroit, MI, USA, 2002.

[15] A. Bentur and S. Mindess, "Fibre reinforced cementitious composites," Modern Concrete Technology Series, Taylor \& Francis, London, NY, USA, 2nd edition, 2007.

[16] M. U. Farooqi and M. Ali, "Contribution of plant fibers in improving the behavior and capacity of reinforced concrete for structural applications," Construction and Building Materials, vol. 182, pp. 94-107, 2018.

[17] A. M. Brandt, "Fibre reinforced cement-based (FRC) composites after over 40 Years of development in building and civil engineering," Composite Structures, vol. 7, 2008.

[18] American Concrete Institute, Building Code Requirements for Structural Concrete (ACI 318-08) and Commentary: An ACI Standard, American Concrete Institute, Farmington, MI, USA, 2008.
[19] P. Peças, H. Carvalho, H. Salman, and M. Leite, "Natural fibre composites and their applications: a review," Journal of Composites Science, vol. 2, no. 4, p. 66, 2018.

[20] Taylor \& Francis, Natural Fibers, Biopolymers, and Biocomposites, A. K. Mohanty, M. Misra, and L. T. Drzal, Eds., Taylor \& Francis, Boca Raton, FL, USA, 2005.

[21] M. S. Huda, L. T. Drzal, D. Ray, A. K. Mohanty, and M. Mishra, "Natural-fiber composites in the automotive sector," in Properties and Performance of Natural-Fibre Composites, pp. 221-268, Elsevier, Amsterdam, Netherlands, 2008.

[22] K. L. Pickering, M. G. A. Efendy, and T. M. Le, "A review of recent developments in natural fibre composites and their mechanical performance," Composites Part A: Applied Science and Manufacturing, vol. 83, pp. 98-112, 2016.

[23] T. Rohan, B. Tushar, and M. G T, "Review of natural fiber composites," IOP Conference Series Materials Science and Engineering, vol. 314, Article ID 012020, 2018.

[24] H. Carvalho, A. Raposo, I. Ribeiro et al., "Application of life cycle engineering approach to assess the pertinence of using natural fibers in composites - the rocker case study," Procedia CIRP, vol. 48, pp. 364-369, 2016.

[25] N. Chand and M. Fahim, Natural Fibers and Their Composites, Elsevier, Amsterdam, Netherlands, 2008.

[26] T. Sathishkumar, P. Navaneethakrishnan, S. Shankar, R. Rajasekar, and N. Rajini, "Characterization of natural fiber and composites - a review," Journal of Reinforced Plastics and Composites, vol. 32, no. 19, pp. 1457-1476, 2013.

[27] G. Marques, J. Rencoret, A. Gutiérrez, and J. C. Del Río, "Evaluation of the chemical composition of different nonwoody plant fibers used for pulp and paper manufacturing," The Open Agriculture Journal, vol. 4, no. 1, pp. 93-101, 2010.

[28] Wiley VCH, Functional Fillers for Plastics, M. Xanthos, Ed., Wiley VCH, Weinheim, Germany, 2005.

[29] A. Gupta and A. Kumar, "Chemical properties of natural fiber composites and mechanisms of chemical modifications," Asian Journal of Chemistry, vol. 24, no. 4, p. 6, 2012.

[30] S. K. Ramamoorthy, M. Skrifvars, and A. Persson, "A review of natural fibers used in biocomposites: plant, animal and regenerated cellulose fibers," Polymer Reviews, vol. 55, no. 1, pp. 107-162, 2015.

[31] M. Thiruchitrambalam, A. Athijayamani, S. Sathiyamurthy, and A. S. A. Thaheer, "A review on the natural fiber-reinforced polymer composites for the development of roselle fiberreinforced polyester composite," Journal of Natural Fibers, vol. 7, no. 4, pp. 307-323, 2010.

[32] J. Cruz and R. Fangueiro, "Surface modification of natural fibers: a review," Procedia Engineering, vol. 155, pp. 285-288, 2016.

[33] D. Rajak, D. Pagar, P. Menezes, and E. Linul, "Fiber-reinforced polymer composites: manufacturing, properties, and applications," Polymers, vol. 11, no. 10, p. 1667, 2019.

[34] L. Mohammed, M. N. M. Ansari, G. Pua, M. Jawaid, and M. S. Islam, "A review on natural fiber reinforced polymer composite and its applications," International Journal of Polymer Science, vol. 2015, Article ID 243947, 15 pages, 2015.

[35] U. Riedel and J. Nickel, "Natural fibre-reinforced biopolymers as construction materials - new discoveries," Die Angewandte Makromolekulare Chemie, vol. 272, no. 1, pp. 34-40, 1999.

[36] M. R. Sanjay, G. R. Arpitha, P. Senthamaraikannan, M. Kathiresan, M. A. Saibalaji, and B. Yogesha, "The hybrid effect of jute/kenaf/E-glass woven fabric epoxy composites for medium load applications: impact, inter-laminar strength, 
and failure surface characterization," Journal of Natural Fibers, vol. 16, no. 4, pp. 600-612, 2019.

[37] G. Musalaiah, B. V. Suresh, M. Tanniru, and P. R. Reddy, "Development and mechanical characterisation OF glass fibre reinforced," Polymer Composite, vol. 8, no. 7, pp. 231-239, 2017.

[38] A. K. Mohanty, M. A. Khan, and G. Hinrichsen, "Surface modification of jute and its influence on performance of biodegradable jute-fabric/biopol composites," Composites Science and Technology, vol. 10, 2000.

[39] T. D. Tavares, J. C. Antunes, F. Ferreira, and H. P. Felgueiras, "Biofunctionalization of natural fiber-reinforced biocomposites for biomedical applications," Biomolecules, vol. 10, no. 1, p. 148, 2020.

[40] Y. G. Thyavihalli Girijappa, S. Mavinkere Rangappa, J. Parameswaranpillai, and S. Siengchin, "Natural fibers as sustainable and renewable resource for development of ecofriendly composites: a comprehensive review," Frontiers of Materials Science, vol. 6, p. 226, 2019.

[41] A. Alawar, A. M. Hamed, and K. Al-Kaabi, "Characterization of treated date palm tree fiber as composite reinforcement," Composites Part B: Engineering, vol. 40, no. 7, pp. 601-606, 2009.

[42] S. M. Rangappa and S. Siengchin, "Natural fibers as perspective materials," International Journal of Animal Science and Technology (IJAST), vol. 11, no. 4, 2018.

[43] T. G. Yashas Gowda, M. R. Sanjay, K. Subrahmanya Bhat, P. Madhu, P. Senthamaraikannan, and B. Yogesha, "Polymer matrix-natural fiber composites: an overview," Cogent Engineering, vol. 5, no. 1, 2018.

[44] M. R. Sanjay, P. Madhu, M. Jawaid, P. Senthamaraikannan, S. Senthil, and S. Pradeep, "Characterization and properties of natural fiber polymer composites: a comprehensive review," Journal of Cleaner Production, vol. 172, pp. 566-581, 2018.

[45] F. R. Oliveira, L. Erkens, R. Fangueiro, and A. P. Souto, "Surface modification of banana fibers by DBD plasma treatment," Plasma Chemistry and Plasma Processing, vol. 32, no. 2, pp. 259-273, 2012.

[46] M. Ravi, R. R. Dubey, A. Shome, S. Guha, and C. Anil Kumar, "Effect of surface treatment on natural fibers composite," IOP Conference Series Materials Science and Engineering, vol. 376, Article ID 012053, 2018.

[47] S. Shahidi, J. Wiener, and M. Ghoranneviss, "Surface modification methods for improving the dyeability of textile fabrics," in Eco-Friendly Textile Dyeing and Finishing, M. Gunay, Ed., InTech, London, UK, 2013.

[48] E. Sinha and S. Panigrahi, "Effect of plasma treatment on structure, wettability of jute fiber and flexural strength of its composite," Journal of Composite Materials, vol. 43, no. 17, pp. 1791-1802, 2009.

[49] J. Morales, M. G. Olayo, G. J. Cruz, P. Herrera-Franco, and R. Olayo, "Plasma modification of cellulose fibers for composite materials," Journal of Applied Polymer Science, vol. 101, no. 6, pp. 3821-3828, 2006.

[50] J. George, M. S. Sreekala, and S. Thomas, "A review on interface modification and characterization of natural fiber reinforced plastic composites," Polymer Engineering \& Science, vol. 41, no. 9, pp. 1471-1485, 2001.

[51] M. N. Belgacem and A. Gandini, "The surface modification of cellulose fibres for use as reinforcing elements in composite materials," Composite Interfaces, vol. 12, no. 1-2, pp. 41-75, 2005.

[52] V. K. Thakur and A. S. Singha, Surface Modification of Biopolymers, John Wiley \& Sons, Hoboken, NJ, USA, 2015.
[53] A. Karthikeyan and K. Balamurugan, "Effect of alkali treatment and fiber length on impact behavior of coir fiber reinforced epoxy composites," Journal of Scientific and Industrial Research, vol. 71, p. 5, 2012.

[54] L. Y. Mwaikambo and M. P. Ansell, "The effect of chemical treatment on the properties of hemp, sisal, jute and kapok for composite reinforcement," Die Angewandte Makromolekulare Chemie, vol. 272, no. 1, pp. 108-116, 1999.

[55] S. Mishra, A. K. Mohanty, L. T. Drzal et al., "Studies on mechanical performance of biofibre/glass reinforced polyester hybrid composites," Composites Science and Technology, vol. 63, no. 10, pp. 1377-1385, 2003.

[56] M. S. Sreekala, M. G. Kumaran, S. Joseph, M. Jacob, and S. Thomas, "Oil palm fibre reinforced phenol formaldehyde composites: influence of fibre surface modifications on the mechanical performance," Applied Composite Materials, vol. 7, pp. 295-329, 2000.

[57] N. Lu, R. H. Swan, and I. Ferguson, "Composition, structure, and mechanical properties of hemp fiber reinforced composite with recycled high-density polyethylene matrix," Journal of Composite Materials, vol. 46, no. 16, pp. 1915-1924, 2012.

[58] A. Atiqah, M. Jawaid, M. R. Ishak, and S. M. Sapuan, "Effect of alkali and silane treatments on mechanical and interfacial bonding strength of sugar palm fibers with thermoplastic polyurethane," Journal of Natural Fibers, vol. 15, no. 2, pp. 251-261, 2018.

[59] M. M. Kabir, H. Wang, K. T. Lau, and F. Cardona, "Chemical treatments on plant-based natural fibre reinforced polymer composites: an overview," Composites Part B: Engineering, vol. 43, no. 7, pp. 2883-2892, 2012.

[60] K. Takemura, Y. Takada, and H. Katogi, "Effect of treatment using silane coupling agent on creep properties of jute fiber reinforced composites," WIT Transactions on The Built Environment, vol. 124, p. 8, 2012.

[61] A. Valadez-Gonzalez, J. M. Cervantes-Uc, R. Olayo, and P. J. Herrera-Franco, "Chemical modification of henequén fibers with an organosilane coupling agent," Composites Part B: Engineering, vol. 30, no. 3, pp. 321-331, 1999.

[62] A. K. Bledzki, A. A. Mamun, M. Lucka-Gabor, and V.S. Gutowski, "The effects of acetylation on properties of flax fibre and its polypropylene composites," Express Polymer Letters, vol. 2, no. 6, pp. 413-422, 2008.

[63] K. C. Manikandan Nair, S. Thomas, and G. Groeninckx, "Thermal and dynamic mechanical analysis of polystyrene composites reinforced with short sisal fibres," Composites Science and Technology, vol. 61, no. 16, pp. 2519-2529, 2001.

[64] H. P. S. Abdul Khalil and H. Ismail, "Effect of acetylation and coupling agent treatments upon biological degradation of plant fibre reinforced polyester composites," Polymer Testing, vol. 20 , no. 1, pp. 65-75, 2000.

[65] J. Gassan and A. K. Bledzki, "The influence of fiber-surface treatment on the mechanical properties of jute-polypropylene composites," Composites Part A: Applied Science and Manufacturing, vol. 28, no. 12, pp. 1001-1005, 1997.

[66] C. Homkhiew, T. Ratanawilai, and W. Thongruang, "Composites from recycled polypropylene and rubberwood flour," Journal of Thermoplastic Composite Materials, vol. 28, no. 2, pp. 179-194, 2015

[67] C. Mei, Y. Fan, L. Mei, and G. Luo, "Surface characteristics OF modified poplar wood-flour and its effect ON the mechanical properties OF wood polymer composites," Reviews on Advanced Materials Science, vol. 33, no. 3, pp. 203-210, 2013. 
[68] A. Ali, K. Shaker, Y. Nawab et al., "Hydrophobic treatment of natural fibers and their composites-A review," Journal of Industrial Textiles, vol. 47, no. 8, pp. 2153-2183, 2018.

[69] M. Zhang, M. Rong, and X. Lu, "Fully biodegradable natural fiber composites from renewable resources: all-plant fiber composites," Composites Science and Technology, vol. 65, no. 15-16, pp. 2514-2525, 2005.

[70] H. U. Zaman, M. A. Khan, R. A. Khan et al., "Role of potassium permanganate and urea on the improvement of the mechanical properties of jute polypropylene composites," Fibers and Polymers, vol. 11, no. 3, pp. 455-463, 2010.

[71] C. Vallo, J. M. Kenny, A. Vazquez, and V. P. Cyras, "Effect of chemical treatment on the mechanical properties of starchbased blends reinforced with sisal fibre," Journal of Composite Materials, vol. 38, no. 16, pp. 1387-1399, 2004.

[72] Y. Chen, N. Su, K. Zhang et al., "Effect of fiber surface treatment on structure, moisture absorption and mechanical properties of Luffa sponge fiber bundles," Industrial Crops and Products, vol. 123, pp. 341-352, 2018.

[73] B. Koohestani, A. K. Darban, P. Mokhtari, E. Yilmaz, and E. Darezereshki, "Comparison of different natural fiber treatments: a literature review," International Journal of Environmental Science and Technology, vol. 16, no. 1, pp. 629-642, 2019.

[74] H. Jamshaid and R. Mishra, "A green material from rock: basalt fiber - a review," The Journal of The Textile Institute, vol. 107, no. 7, pp. 923-937, 2016.

[75] R. Aravind and A. Das, "Experimental investigation on the fracture behaviour of steel fiber," Reinforced Concrete, vol. 04, no. 04, p. $10,2017$.

[76] S. Thomas, Functionalized Engineering Materials and Their Applications, Apple Academic Press, Palm Bay, FL, USA, 1st edition, 2018.

[77] M. Serdar, A. Baričević, M. Jelčić Rukavina, M. Pezer, D. Bjegović, and N. Štirmer, "Shrinkage behaviour of fibre reinforced concrete with recycled tyre polymer fibres," International Journal of Polymer Science, vol. 2015, Article ID 145918, 9 pages, 2015.

[78] K. V. krishna, J. Venkateswara Rao, and J. V. Rao, "Experimental study on behavior of fiber reinforced concrete for rigid pavements," IOSR Journal of Mechanical and Civil Engineering, vol. 11, no. 4, pp. 49-53, 2014.

[79] J. F. Castillo-Lara, E. A. Flores-Johnson, A. Valadez-Gonzalez et al., "Mechanical properties of natural fiber reinforced foamed concrete," Materials, vol. 13, no. 14, p. 3060, 2020.

[80] I. Sanal and D. Verma, "Construction materials reinforced with natural products," in Handbook of Ecomaterials, L. M. T. Martínez, O. V. Kharissova, and B. I. Kharisov, Eds., Springer International Publishing, Berlin, Germany, pp. 1-24, 2018.

[81] F. Wafa, "Properties \& applications of fiber reinforced concrete," Journal of King Abdulaziz University-Engineering Sciences, vol. 2, no. 1, pp. 49-63, 1990.

[82] P. Sahu and M. Gupta, "A review on the properties of natural fibres and its bio-composites: effect of alkali treatment," Proceedings of the Institution of Mechanical Engineers, Part L: Journal of Materials: Design and Applications, vol. 234, no. 1, pp. 198-217, 2020.

[83] D. Sun, "Surface modification of natural fibers using plasma treatment," in Biodegradable Green Composites, S. Kalia, Ed., John Wiley \& Sons, Hoboken, NJ, USA, pp. 18-39, 2016.

[84] S. Kalia, K. Thakur, A. Celli, M. A. Kiechel, and C. L. Schauer, "Surface modification of plant fibers using environment friendly methods for their application in polymer composites, textile industry and antimicrobial activities: a review," Journal of Environmental Chemical Engineering, vol. 1, no. 3, pp. 97-112, 2013.

[85] Ikramullah, S. Rizal, S. Thalib, and S. Huzni, "Hemicellulose and lignin removal on Typha fiber by alkali treatment," IOP Conference Series Materials Science and Engineering, vol. 352, Article ID 012019, 2018.

[86] H. Chen, W. Zhang, X. Wang et al., "Effect of alkali treatment on wettability and thermal stability of individual bamboo fibers," Journal of Wood Science, vol. 64, no. 4, pp. 398-405, 2018.

[87] L. Yan, N. Chouw, L. Huang, and B. Kasal, "Effect of alkali treatment on microstructure and mechanical properties of coir fibres, coir fibre reinforced-polymer composites and reinforced-cementitious composites," Construction and Building Materials, vol. 112, pp. 168-182, 2016.

[88] M. Asim, M. Jawaid, K. Abdan, and M. R. Ishak, "The effect of silane treated fibre loading on mechanical properties of pineapple leaf/kenaf fibre filler phenolic composites," Journal of Polymers and the Environment, vol. 26, no. 4, pp. 15201527, 2018.

[89] R. Agrawal, N. S. Saxena, K. B. Sharma, S. Thomas, and M. S. Sreekala, "Activation energy and crystallization kinetics of untreated and treated oil palm fibre reinforced phenol formaldehyde composites," Materials Science and Engineering: $A$, vol. 277, no. 1-2, pp. 77-82, 2000.

[90] V. Tserki, N. E. Zafeiropoulos, F. Simon, and C. Panayiotou, "A study of the effect of acetylation and propionylation surface treatments on natural fibres," Composites Part A: Applied Science and Manufacturing, vol. 36, no. 8, pp. 11101118, 2005.

[91] R. Ahmad, R. Hamid, and S. A. Osman, "Physical and chemical modifications of plant fibres for reinforcement in cementitious composites," Advances in Civil Engineering, vol. 2019, Article ID 5185806, 18 pages, 2019.

[92] M. Ramesh and L. Kenaf Hibiscus Cannabinus, "Kenaf (Hibiscus cannabinus L.) fibre based bio-materials: a review on processing and properties," Progress in Materials Science, vol. 78-79, pp. 1-92, 2016.

[93] X. Li, L. G. Tabil, and S. Panigrahi, "Chemical treatments of natural fiber for use in natural fiber-reinforced composites: a review," Journal of Polymers and the Environment, vol. 15, no. 1, pp. 25-33, 2007.

[94] M. George, P. G. Mussone, and D. C. Bressler, "Surface and thermal characterization of natural fibres treated with enzymes," Industrial Crops and Products, vol. 53, pp. 365-373, 2014.

[95] N. Lu, S. Oza, and M. G. Tajabadi, "Surface modification of natural fibers for reinforcement in polymeric composites," in Surface Modification of Biopolymers, V. K. Thakur and A. S. Singha, Eds., John Wiley \& Sons, Hoboken, NJ, USA, pp. 224-237, 2015. 